\section{O Serviço \\ Social e suas particularidades histórico- -profissionais ao redor do mundo}

\section{Social Work and its \\ historical-professional diversity around the world}

\author{
Marileia Goin ${ }^{a}$ \\ (D) https://orcid.org/0000-0003-4859-3098
}

Resumo: Este artigo objetiva dialogar com o Serviço Social ao redor do mundo, a partir de uma interlocução profícua com as produções reunidas na coletânea Serviço Social na história, publicada pela Cortez Editora. Nessa perspectiva, a produção privilegia sintonizar a profissão e seus fundamentos no bojo das peculiaridades históricas dos países, as quais imprimem selo distinto e particular à profissão, em face da sua relação orgânica com a realidade.

Palavras-chave: Serviço Social. Fundamentos. História.

Abstract: This article aims to dialogue with Social Work around the world, based on a fruitful dialogue with the productions gathered in the collection Social Work in History, published by Cortez Publishing
House. In this perspective, this essay focuses in balancing the profession and its grounds in the midst of the countries' historical peculiarities, which give a distinctive and particular badge to the profession, in view of its organic relationship with reality.

Keywords: Social Work. Fundamentals. History.

\section{Introdução}

abordagem acerca da emergência
do Serviço Social no mundo não está consensuada na literatura profissional e, tampouco, é tratada de forma convergente entre pesquisadores/as. Enquanto uns/umas a entendem no bojo das respostas da ação social às relações produtivas oriundas da Revolução Industrial, na Inglaterra, outros/as a demarcam a partir da mirada para a ciência ocorrida do outro lado do Atlântico, em solo estadunidense - efetivamente deslocada do caráter assistencial e do voluntariado inglês. ${ }^{1}$

Embora soem como emblemáticas, tais divergências tornam-se palatáveis quando nos aproximamos da diversidade profissional ao redor do mundo e, consecutivamente, das distintas concepções

Para adensar tais perspectivas, consultar: Goin (2019a); Miranda Aranda (2009); e Martinelli (2003). 
acerca dos Fundamentos do Serviço Social em cada país. São com "essas vozes nem sempre consensuais" (Iamamoto e Yazbek, 2019, p. 12) que nos propomos a dialogar nessa produção, a partir de uma revisão respeitosa e cuidadosa com a obra Serviço Social na história: América Latina, África e Europa, publicada pela Cortez Editora, no ano de 2019, a qual ocupa de maneira seminal "uma lacuna na produção acadêmica brasileira quanto ao conhecimento do Serviço Social no circuito mundial nas últimas décadas" (Iamamoto e Yazbek, 2019, p. 11).

Nela não só encontramos a representação de três continentes (americano, africano e europeu), mas também as particularidades nacionais que são terreno privilegiado para sintonizar o Serviço Social, seu significado social e suas metamorfoses ao longo do seu processo sócio-histórico. Aliás, do início ao fim, o livro privilegia a diversidade como "marca decisiva do Serviço Social nesse universo" (Iamamoto e Yazbek, 2019, p. 12).

Nessa esteira introdutória, o artigo objetiva aproximar-se do Serviço Social (e seus fundamentos) e de suas particularidades histórico-profissionais ao redor do mundo, a partir dos textos reunidos na coletânea em questão, tendo como radares de análise a gênese, a formação em Serviço Social, o trabalho profissional, as perspectivas teórico-metodológicas e o projeto profissional, assim como o protagonismo das entidades organizativas da categoria.
Sem a pretensão de esgotar o debate, o horizonte é possibilitar a aproximação à profissão em diferentes países e demonstrar, por meio desta resenha, o quão necessária é a ultrapassagem das fronteiras geográficas brasileiras, para entendermos o quanto avançamos desde a constituição da profissão no Brasil, as conquistas históricas (coletivas) da categoria e as lutas que permanecem sendo travadas para continuarmos disputando esse árdua trilha histórico-profissional.

\section{$\mathrm{O}$ ato de resenhar o Serviço Social ao redor do mundo: configurações histórico- -profissionais}

No bojo da heterogeneidade mundial, as particularidades não são dispensadas. Aliás, elas são constitutivas de uma universalidade complexa, permeada de peculiaridades nacionais e de trajetórias concernentes às suas metamorfoses. É nesse sentido diverso que a profissão se insere nos países e, por essa via, conduz ao seu significado social, ao seu modo de ser, à sua legitimidade e aos traços que a caracterizam, assim como a sua/s concepção/ões.

Indispensável sintonizar que, sob a ótica brasileira - marcos geográficos e territoriais onde nos inserimos -, o entendimento do Serviço Social e de seus Fundamentos ${ }^{2}$ perpassa: (1) o seu

\footnotetext{
2 Entende-se por Fundamentos "os elementos que (a) alicerçam e assentam as bases da
} 
reconhecimento na divisão social e técnica do trabalho, (2) a sua inserção em processos de trabalho coletivos, (3) a existência de um objeto profissional "questão social" -, (4) a conquista de um conjunto de atividades exclusivas (atribuições privativas), que pecualiarizam a inserção e o trabalho do/a assistente social no âmbito das instituições que o/a contratam; (5) as dimensões teórico-metodológicas e ético-políticas que, reunidas, conduzem a uma dimensão técnico-operativa qualificada, combativa do imobilismo, do pragmatismo e do obscurantismo - tão presentes em intervenções desprovidas de direcionamento,

formação e do trabalho profissional ao longo de sua trajetória sócio-histórica e (b) conferem configuração particular à profissão em face da processual e orgânica relação com a realidade, interpondo-lhes a necessária apropriação das matrizes de conhecimento do social e do movimento da sociedade para prover de direção social e política o trabalho profissional, seja por viés conservador, seja emancipatório" (Goin, 2019a, p. 31). Eles afirmam "[...] a matriz explicativa da sociedade burguesa e da profissão na interlocução entre o Serviço Social e a sociedade, abrangendo múltiplas dimensões: históricas, teórico-metodológicas, ético-políticas e técnico-operativas. Eles também englobam a abordagem histórico-crítica, fundada na teoria social marxiana, incorporando o movimento d[a] história. São, assim, elementos essenciais dessa abordagem a concepção de profissão no movimento histórico da sociedade capitalista; a 'questão social' e suas expressões, âmbito privilegiado do exercício profissional; e o trabalho como categoria fundante para analisar o exercício do Serviço Social na sociedade capitalista" (Yazbek, 2009, 2018, apud Yazbek e Iamamoto, 2019, p. 516). que não sabem aonde querem chegar e, por isso, centradas no "como fazer" profissional.

Ademais, é na relação entre profissão e realidade que se evidenciam as particularidades nacionais e as distintas requisições profissionais, uma vez que as profissões são construções históricas e sociais que ganham significado e inteligibilidade quando analisadas no âmbito do movimento das sociedades nas quais se inserem (Raichelis, 2009) e, por isso, “a história da sociedade é terreno privilegiado para apreensão das particularidades do Serviço Social: seu modo de atuar e de pensar incorporados e construídos ao longo de seu desenvolvimento" (Yazbek e Iamamoto, 2019, p. 514, grifos das autoras).

Em face disso, a profissão se encontra estreitamente atrelada aos desafios conjunturais, dentre os quais auferem evidência as transformações observadas nas últimas décadas no âmbito da acumulação capitalista, com interfaces na reestruturação produtiva e na financeirização da economia, com impactos no mundo do trabalho, nas políticas sociais e nas relações contraditórias entre os/as que detêm os meios de produção e os/as que dispõem única e exclusivamente da sua força de trabalho; a desqualificação e a despolitização da esfera da política; e o avanço do conservadorismo sem precedentes (Yazbek, 2019), com alicerces protofascistas, que refletem externa e internamente no Serviço Social. 
Historicamente, o Serviço Social não fica fora de tais determinações, motivo pelo qual é necessário constituir mediações que o relacionem com as diferentes esferas da vida social no mundo hegemonizado pelo capital (Ávila e Londoño, 2019). Desde a gênese da profissão, ao redor do mundo, não é incomum encontrar a interferência da Igreja Católica. Apesar de amplamente conhecida sua incidência na constituição da escola chilena, ${ }^{3}$ em 1929 - primeira escola católica da América Latina e do Caribe - , e seu espraiamento pela região latino-americana, a Igreja Católica atravessa mares e oceanos, em tempos, décadas e conjunturas distintas - França (1907), Suécia (1910), Chile (1929), Argentina (1930), Portugal (1935), Brasil (1936), Colômbia (1936) e Angola (1962) — para asseverar sua hegemonia e buscar mecanismos de proteção e ampliação dos espaços de difusão do seu pensamento, em um cenário de perda de poder e privilégios sustentados durante o feudalismo.

Apesar dessa característica que unifica os países indicados, os rumos profissionais pouco a pouco refutam os "problemas morais", relativos à gênese católica, e constituem caminhos peculiares à sua inserção no circuito capitalista mundial, ao passo que o mercado passa

3 Escola Elvira Matte de Cruchaga, primeira escola denominadamente católica da América Latina e do Caribe. Para mais informações, consultar Goin (2019a). a regular as relações sociais de forma suprema e a profissão, como constitutiva dessa sociedade de mercado, se metamorfoseia para manter sua necessidade e existência social.

Em tempos diferentes - e de modo especial no cenário atual, de crise estrutural do capital e de interferências nas diversas esferas da vida social, em que se engendram novas crises e uma sociabilidade conservadora (Yazbek, 2019) -, a formação em Serviço Social, atrelada ao trabalho assalariado, é requisitada a dialogar com o "emaranhado de contradições e correlações de forças que se estabelece em torno da riqueza socialmente produzida, apropriada privadamente pelo capital para fins de acumulação" (Raichelis, 2019, p. 70).

Brasil, Colômbia e Portugal, por exemplo, cada um a seu modo, contabilizam mais de oito décadas desde a constituição da profissão. Diferentemente dos dois primeiros, que são historicamente marcados por traços coloniais e de exploração, subjugados à periferia do capital, Portugal tem suas marcas na conquista e no domínio de territórios, dentre eles Brasil e Angola.

A formação da primeira escola de Serviço Social em Portugal, em 1935, ocorre em meio à ditadura conduzida, em grande parte, por António de O. Salazar, que foi deposta apenas em 1974. Durante esse período, o mundo foi atravessado pela II Guerra Mundial em que Portugal, após adotar uma política 
externa de neutralidade, manteve o diálogo bilateral com ambas as forças beligerantes. Tal posição, no plano externo, refletia internamente a necessidade de a ditadura salazarista fomentar mecanismos ideológicos de hegemonia que estimulassem um sentimento de consenso de classes, característica transversal nas principais ditaduras fascistas em todo o mundo. Sobretudo, é a partir do término da ditadura salazarista, ininterrupta por mais de quatro décadas, que o Serviço Social, assim como abordam Martins e Tomé (2019), se envolve nas lutas sociais e na construção de um projeto profissional.

A adesão à Declaração de Bolonha impacta no Serviço Social, assim como na educação como um todo, e resulta (1) na formação em ciclos, sendo o primeiro voltado à formação para "o mercado de trabalho, o segundo, conducente ao grau de mestre, para aprofundamento dos conhecimentos já obtidos e para especializar para a investigação e para a profissão" (Martins e Tomé, 2019, p. 390), e o terceiro, por sua vez, correspondente ao doutoramento; (2) no aumento dos custos da formação, que varia de acordo

4 A Declaração de Bolonha foi assinada em 1999 entre ministros da Educação de diversos países da Europa e, a partir da construção de um Espaço Europeu de Educação Superior, constitui-se em um marco de referência para as reformas universitárias, pelas quais a educação superior passa a ser dimensionada por interesses não só econômicos, mas também políticos. com o tempo de duração e com a natureza pública ou privada da instituição de ensino; ${ }^{5}$ e (3) no cômputo de 17 cursos de $1^{\circ}$ ciclo, dos quais dez são públicos, conforme dados de 2019 (Martins e Tomé, 2019). Apesar de a população portuguesa passar pouco mais de 10 milhões de habitantes (2019) e de o Brasil contabilizar mais de 210 milhões (2018), é fulcral apontar que, em termos quantitativos, o Serviço Social brasileiro possui uma oferta aproximadamente $30 \%$ maior que a portuguesa, considerando os dados do Instituto Anísio Teixeira (Inep), de 2018, que indicavam 451 cursos no Brasil. ${ }^{6}$

Em cooperação com a Pontifícia Universidade Católica de São Paulo, é criado o primeiro mestrado (1987) e doutorado (1997) na área que, além de prodigiosos na qualificação acadêmica, rebateram diretamente no trabalho profissional. São sob estes auspícios que

[...] a categoria profissional inicia o debate e a proposta de criação da Ordem dos Assistentes Sociais (OAS), configurando a construção de um projeto profissional, regulador da formação e do exercício da profissão, norteado por valores éticos e políticos de compromisso

5 Dados de 2005 revelam que enquanto as mensalidades nas instituições privadas giravam em torno de sete salários mínimos portugueses, nas públicas esse montante estava em torno de dois salários (Martins e Tomé, 2019).

6 Para maiores informações, consultar Goin (2019b). 
com a efetividade dos direitos sociais e humanos e a defesa de uma sociedade justa sem discriminação de qualquer natureza (Martins e Tomé, 2019, p. 388).

Promulgada a lei que cria a OAS em 2019, igualmente significativa nesse mesmo ano é a constituição da Sociedade Científica em Serviço Social, que tem o intuito de contribuir com a consolidação acadêmica do Serviço Social português e com a produção do conhecimento científico na área. Entretanto, a tardia regulamentação profissional ainda constitui um dos mais significativos desafios aos/às assistentes sociais portugueses, na medida em que não só fragiliza a articulação entre formação, trabalho e organização política (Martins e Tomé, 2019), como também relega ao segundo plano a constituição de um projeto profissional ética e politicamente referenciado.

$\mathrm{Na}$ envergadura da diplomação na área, a profissão não só registrou seu crescimento exponencial - que, entre acréscimo e decréscimo, registra aumento significativo nas últimas décadas -, como também a ampliação dos espaços sócio-ocupacionais, sendo a carreira Técnica Superior de Serviço Social na administração pública, em 1991, seu principal exemplo.7 Como evidenciam Martins e Tomé (2019), se uma parte

7 Carreira que foi extinta com a reforma da administração pública, em 2008. do contingente profissional é absorvida pelos serviços públicos, com melhores salários, direito a férias e horário de trabalho reduzido, a outra está vinculada aos serviços privados, de natureza lucrativa ou sem fins lucrativos, nos quais prevalecem a flexibilização e a desregulamentação das relações de trabalho, contratos precários, polivalência, trabalho aos fins de semana e feriados, folgas rotativas, baixos salários, múltiplos vínculos, estímulo à pejotização e ao empreendedorismo, num cenário de crescente destituição de direitos e de "incorporação da 'ideologia gerencialista' [que] esvazia conteúdos reflexivos e criativos do trabalho, enquadrando processos e dinâmicas institucionais às metas de controle de qualidade e de produtividade a serem alcançadas" (Raichelis, 2019, p. 71).

O cenário de crise do capitalismo contemporâneo e de mundialização financeirizada dos capitais impacta diretamente na gestão e na organização do trabalho, pois gera

[...] processos continuados de informalização e flexibilização dos contratos de trabalho por meio de trabalhos terceirizados, subcontratados, temporários, em domicílio, em tempo parcial ou por tarefa/projeto, para citar apenas algumas das diferentes formas de precarização a que estão submetidos os trabalhadores no "novo e (precário) mundo do trabalho" (Alves, 2000). Essas metamorfoses atingem duramente o trabalho assalariado, 
sua realização concreta e as formas de (des)subjetivação na consciência dos trabalhadores, com impactos nas dinâmicas associativas, organizativas e na afirmação de identidades coletivas (Raichelis, 2019, p. 71).

Independentemente da natureza institucional (pública ou privada), a desvalorização salarial dos/as assistentes sociais tem sido uma constante - chegando a aproximadamente dois salários mínimos portugueses - juntamente ao processo de desprofissionalização desencadeado pela privatização dos serviços públicos (Martins e Tomé, 2019).

Nessa via, é notório que fazem parte da realidade histórico-profissional dos/ as assistentes sociais portugueses as mudanças formativas a partir de Bolonha, a ampliação dos custos de formação, a fragilização dos vínculos de trabalho, os baixos salários e o consecutivo escamoteio da centralidade das discussões sobre projeto profissional.

Em terras latino-americanas, por sua vez, as particularidades histórico-profissionais diferem em relação à portuguesa, uma vez que sua inserção no circuito mundial se opera a partir do metabolismo do capital monopolista na periferia mundial.

O desenrolar de uma economia dependente com pouco desenvolvimento das forças produtivas, regulada por relações de subordinação ao capital transnacional, constitui um sistema de produção e reprodução social que, inserido no sistema mundo, apresenta altos níveis de superexploração e pauperismo (Ávila e Londoño, 2019, p. 244).

Como produto das condições e demandas oriundas do desdobramento das relações sociais, a criação da primeira escola de Serviço Social na Colômbia, em 1936, combinou as requisições do Estado, em face do avanço do capitalismo monopolista, e as orientações da hierarquia católica. Dessa maneira, o Serviço Social colombiano é encarregado de atender às requisições de seu maior empregador, o Estado, com respostas "especializadas" às demandas do capital e das classes trabalhadoras (Ávila e Londoño, 2019).

Nos limites de uma economia periférica e dependente, a luta de classes na Colômbia se intensifica no decorrer das primeiras décadas da segunda metade do século XX, assim como na América Latina como um todo, e promove não só a organização da classe trabalhadora, ${ }^{8}$

8 "A classe trabalhadora se manifesta por meio da luta sindical; partidos políticos como o Comunista fortalecem sua incidência em algumas regiões; acrescenta-se a luta camponesa com organização como a ANUC (Associação Nacional de Usuários Camponeses); há visibilidade e capacidade de luta dos povos indígenas, representados pela ONIC (Organização Nacional de Indígenas da Colômbia); os estudantes propiciam um novo contexto na área da educação através da FUN (Federação Universitária Nacional), principalmente nas universidades públicas; 
mas também cria condições objetivas para repensar a relação entre profissão e realidade. Nesse período, o processo renovador colombiano se inscreve no bojo do Movimento de Reconceituação na América Latina, que teve como principais vetores, segundo Netto (2007): (1) a crise das ciências sociais, que passam por um processo de renovação; (2) o fortalecimento do movimento estudantil; e (3) a renovação da Igreja Católica. Mais do que fatores externos à profissão, eles levantam indagações político-ideológicas acerca da condução profissional, em face das transformações políticas, econômicas e sociais da realidade latino-americana. Indistintamente, o processo então instaurado constitui um dos marcos fundamentais do Serviço Social na América Latina, por meio de

[...] um movimento de denúncia e contestação ao "Serviço Social Tradicional", com o consecutivo rechaçamento executivo e a valorização do estatuto intelectual, na metade da década de 1960. Longe de se revelar como um conjunto monolítico, o processo então iniciado canalizou esforços para (re)pensar a profissão no âmbito das mudanças da sociedade latino-americana, em face

criam-se fortes movimentos sociais, como o Frente Unido, liderado por Camilo Torres, e a ANAPO (Aliança Nacional Popular), ao mesmo tempo em que surgem distintos grupos guerrilheiros, como as Forças Armadas Revolucionárias da Colômbia (FARC), Exército de Libertação Nacional (ELN) [...]" (Ávila e Londoño, 2019, p. 249). de os pressupostos doutrinários e as técnicas elaboradas em outras latitudes demonstrarem inoperância diante das reais demais do "homem concreto" (Goin, 2019a, p. 89).

Apesar do atrelamento ao movimento crítico de nível regional, no Serviço Social colombiano, contemporaneamente, ainda prevalece uma formação instrumental, utilitarista e pragmática, cuja dimensão prática impera sobre a teórica - não dispõe de uma unidade, mas de sobreposição e do desprestígio da dimensão teórica e do caráter político em detrimento do operativo. Esses "processos que reforçam a formação pragmática e utilitarista do conhecimento, na qual a teoria deve estar a serviço de sua aplicabilidade imediata, que despreza o cultivo às abstrações e à apreensão da totalidade histórica e reproduz a falsa dicotomia entre conhecimento teórico e prática social" (Raichelis, 2019, p. 79) tornam o discurso pós-moderno mais permeável, "considerando ainda, a ausência, em grande parte, dos(as) jovens que ingressam na universidade, de socialização da política em movimentos sociais, sindicatos, partidos e/ou coletivos de luta da classe trabalhadora" (Raichelis, 2019, p. 79). Ademais, com expressivos componentes tradicionais - que, por sua vez, tornam diminutas as pesquisas sobre a mercantilização do ensino e sobre a formação a distância, existentes há vários anos no país (Ávila e Londoño, 2019) -, 
[...] reativa-se o pensamento conservador, restaurador e defensor da ordem instituída e o pensamento reacionário, que confronta valores democráticos e propõe a eliminação de direitos. Emerge uma sociabilidade e uma nova política inscritas na agenda neoliberal, pois as transformações em andamento correm não apenas em relação à ordem econômica, mas constituem um conjunto de mudanças e processos assimétricos e desiguais que atingem múltiplas dimensões da vida social. [...] A nova sociabilidade e a nova política, inscritas na agenda neoliberal, vêm provocando metamorfoses no campo da subjetividade, expressas no individualismo competitivo exacerbado, pressionado pelo consumo e que vive com um grau de incerteza e ansiedade sem precedentes. Fragmentam-se as diferentes esferas da vida social e referências culturais e simbólicas que tornavam o mundo reconhecível são colocadas em questão (Yazbek, 2019, p. 94).

É indispensável apontar que, diferentemente do português, o Serviço Social colombiano é regulamentado pela Lei n. 53, de 1977, com Decreto Regulamentar n. 2.833, de 1981, o qual também cria o Conselho Nacional de Trabalho Social, ${ }^{9}$ instância político-organizativa que reúne diferentes entidades profissionais e é responsável, em território nacional, pela carteira profissional e,

9 Assemelha-se ao Conselho Federal de Serviço Social (CFESS), no Brasil. consecutivamente, pelo zelo ao trabalho profissional. Além disso, a profissão dispõe de Código de Ética ${ }^{10}$ que somado à regulamentação se constituem em elementares instrumentos jurídicos no âmbito da categoria profissional na Colômbia, apesar da ausência de um explícito projeto profissional ético e político hegemônico - o que não quer dizer que não exista, pois desde o Movimento de Reconceituação a suposta neutralidade profissional vem sendo colocada em xeque.

Em outras latitudes, o Serviço Social angolano se particulariza do português e do colombiano. No caso de Angola, que se independentiza em 1975 e tem sua sociedade historicamente marcada pelo colonialismo e pelos processos sócio-históricos externos - fim da II Guerra Mundial; mundo dividido em face da busca de hegemonia mundial, sobretudo dos países periféricos e emergentes; surgimento de países não alinhados com os blocos em conflito; florescimento da classe operária na Europa e do avanço dos ideais socialistas; independência de países africanos sob a inspiração socialista (Monteiro, 2019) —, o Serviço Social que nasce em face do alargamento do Estado tem suas características "modernas" constituídas sob as bases do "arcaico", sem rupturas com as relativas

10 Conforme Ávila e Londoño (2019), no decorrer da história, o Serviço Social colombiano teve aprovados três Códigos de Ética, datados de 1981, 2002 e o vigente, de 2015. 
ao tempo colonial, cujas bases estiveram ancoradas em "vertentes teórico-metodológicas positivistas fundadas numa sociologia empirista e de inspiração funcionalista-sistêmica, com forte pendor doutrinal católico de inspiração tomista ou neotomista" (Monteiro, 2019, p. 372).

Num cenário de crescimento da economia, em que: "agravam-se as condições de vida da população, as taxas de inflação atingem níveis elevadíssimos, não permitem poupanças e as taxas de desemprego são igualmente altíssimas" (Santo, 2019, p. 353), a formação é demandada e legitimada pelo Estado capitalista, ${ }^{11}$ ao vislumbrar reformas dentro da mesma ordem que a demanda, e a legitima como profissão a partir de princípios norteadores que tratam os processos sociais isolados e responsabilizam os sujeitos pela sua condição individual - a chamada psicologização do social. Nessa esteira, ao referir as tendências que interferem decisivamente nas respostas institucionais à "questão social", Iamamoto (2019) assevera: (1) o reforço ao individualismo e a responsabilização da família pela superação da pobreza, ao transferir para os sujeitos e sua família a responsabilidade pelo enfrentamento às desigualdades; (2) a moralização da "questão social", em que a tendência é encarar a pobreza como

11 Nos termos de Monteiro (2019, p. 370), o "novo" Estado não é "mais colonialista, nem socialista, mas capitalista, aberto à economia de mercado e ao pluripartidarismo". questão psicológica e, por essa via, sua aceitação perpassaria a via terapêutica, individual e familiar; e (3) a assistencialização da barbárie do capital e a criminalização de suas manifestações, que reiteram repressão e assistência no trato das contradições de classes.

Passados 28 anos de "luto e congelamento" da profissão em território angolano $^{12}$ - termos utilizados por Monteiro (2019) —, sua reinstituição em 2005 sob mando católico, institucionalizado na atual Universidade Católica de Angola - se dá em nível superior, "com duração de quatro anos e proporciona uma formação científica, técnica, moral e doutrinária" (Monteiro, 2019, p. 371), da gênese aos dias atuais. Entretanto, é na virada da primeira década do século XXI que a formação graduada (para os/ as angolanos/as, licenciada) aufere reforço de caráter estatal e pós-graduada, esta sob colaboração direta do Programa de Estudos Pós-Graduados da Pontifícia Universidade Católica de São Paulo, assim como ocorreu em Portugal.

Ao sistematizar as características profissionais contemporâneas, Monteiro (2019, p. 372, grifos nossos) indica que

[...] a formação do Assistente Social em Angola está voltada para a intervenção;

12 Logo após proclamada a independência de Angola (1975), a única escola de formação em Serviço Social é extinta e, assim, a formação é retomada apenas nos idos de 2005 (Monteiro, 2019). 
uma formação com clara preocupação com a tecnificação do profissional, caracterizada por um aparato de disciplinas voltadas ao domínio da informática, gestão de projetos sociais, entre outras; inexistência de uma corrente ou teoria social como privilegiada ou "hegemônica”, o que coloca fronteiras muito tênues entre um ecletismo desavisado e um pluralismo inconsciente; presença das noções de Serviço Social com "casos", "grupos" e "comunidades"; forte presença da visão católica e moderna sobre a "questão social" e seus modos de enfrentamento, constantes pelo menos nos documentos oficiais que orientam a prática formativa [...].

Apesar da inexistência de Código de Ética - vale lembrar que, dependendo dos valores que inspiram as intervenções socioinstitucionais do Assistente Social, podem "ser mecanismo de violações voluntárias ou inconscientes dos sujeitos que são demandantes e/ou usuários do trabalho profissional do Assistente Social" (Monteiro, 2019, p. 377) —, o Serviço Social angolano dispõe da Associação dos Assistentes Sociais que, juntamente às Escolas de Serviço Social, reconhece como usuários/as os sujeitos que utilizam as políticas sociais, considerando que a luta pelos direitos é conquista dos movimentos sociais organizados, dos quais a profissão participa (Monteiro, 2019).

Em relação ao trabalho profissional, Monteiro (2019, p. 374) elucida que "o Estado é o principal consumidor da força de trabalho do Assistente Social em Angola, sobretudo através dos setores de saúde, de políticas voltadas à proteção e de educação de crianças, seguindo os setores de ordem, de defesa e de segurança”, embora parcela significativa não exerça a função de assistente social propriamente dita, pois não existe o cargo no quadro orgânico das instituições.

Assim como Portugal e Colômbia, o Serviço Social angolano também não dispõe de um projeto profissional coletivo, que dirige e norteia ética, política e conscientemente a profissão. ${ }^{13}$ Apesar da indefinição de um projeto dessa magnitude, não significa dizer que a profissão se desenvolva destituída de orientação teleológica. Aliás, essa dimensão está impressa em toda intervenção, seja ela inspirada em qualquer tendência teórico-metodológica ou doutrinária. 0 que estamos enfatizando é que a ausência de um projeto profissional coletivo - que não é corporativo porque é dotado de caráter ético e político e, por isso, elevado a uma dimensão de universalidade - ,

13 "[...] construir o projeto ético-político da profissão em Angola constitui [um] desafio que, entre outras coisas, pressupõe investir em mediações políticas capazes de superar heranças e presenças conservadoras que alimentam gestões autoritárias e integralistas por um lado, e, por outro, possam dar uma direção política ao quadro da 'relativa autonomia' da profissão que, em Angola, sob pena de simplesmente abraçar de modo quase 'natural' o ideário conservador que lhe deu origem, quer no tempo colonial como na atualidade" (Monteiro, 2019, p. 377). 
como dispõe Iamamoto (2019), dificulta a articulação entre o dever ser profissional e o exercício concreto da profissão no contexto das condições contraditórias de realização, mediadas pelo estatuto assalariado e pela organização política das classes. Ademais, amplia, em escala vertiginosa, as seduções ao imobilismo, ao trabalho repetitivo, à centralidade da técnica, à premência do quantitativo em detrimento do qualitativo e ao provimento de uma razão instrumental, embebida de irreflexão e praticismo.

No bojo das linhas escritas, ficam nítidas as particularidades histórico-profissionais dos países abordados - e que não se limitam a eles, mas são uma amostra promissora para sintonizar o Serviço Social ao redor do mundo - , as quais resultam em instigante e profícuo desocultamento da inserção da profissão no circuito internacional, tão necessário na trama da (re)produção do capitalismo contemporâneo.

Esse revigorante livro se insere e nos brinda com análises e reflexões no “[...] solo movente, imprevisível e prenhe de possibilidades, contradições e limites para esta profissão/área do conhecimento, cujas requisições societárias e inscrição no processo social são fortemente sensíveis ao contexto" (Behring, 2019, s. p.). Ademais, permite reconhecer a diversidade do Serviço Social no mundo e os seus desafios históricos frente às condições prementes deste início de século no universo espelhado.

\section{Considerações finais}

Uma obra de contribuição inestimável. Rigor científico, diversidade e internacionalização, como vimos nas linhas resenhadas, são características orgânicas dessa coletânea, que sob os olhos nativos permite o diálogo entre realidades ao redor do mundo tão particulares e, ao mesmo tempo, reveladoras de eixos convergentes, marcas de sua história.

Assim como o título da coletânea anuncia, a "viagem profissional" entre o continente americano, africano e europeu é inspiradora, ao passo que nos aproxima de regiões geograficamente distantes, mas ao mesmo tempo próximas em termos profissionais, porque as particularidades profissionais relativas a cada país revelado não destoam de um feroz capitalismo contemporâneo, capitaneado pelo capital produtivo internacional, pelo capital que rende juros e pela radicalização de raiz liberal e privatista.

As "reveladas dimensões do processo de institucionalização e desenvolvimento do Serviço Social na história dos países e suas metamorfoses - o que já é uma contribuição exemplar e inédita" (Yazbek e Iamamoto, 2019, p. 514, grifos das autoras) - não param por aí. Seu ineditismo permite que o/a leitor/a seja interlocutor/a no circuito internacional, ao possibilitar a apreensão dos desafios imensuráveis colocados à profissão, em termos de formação, trabalho ou direcionamento profissional, no contexto desse tempo histórico. 
Nesse sentido, a preocupação evidenciada na introdução do presente artigo de resenhar de forma respeitosa e cuidadosa, da primeira à última linha, teve como pressuposto não comparar realidades tão distintas e diversas, no bojo de processos sócio-históricos dos países aqui selecionados, mas dar "voz" aos/às autores/as nativos/as, os quais são as veias que pulsam e movimentam a profissão nas fronteiras nacionais.

"Esta publicação [que] oferece um rico acervo de contribuições acerca dos fundamentos do Serviço Social com distintas formas de explicar a profissão e área de conhecimento e para o exercício de suas atividades no âmbito das relações entre o Estado e a sociedade de classes" (Yazbek e Iamamoto, 2019, p. 511) preenche uma lacuna aberta entre a interlocução da produção do conhecimento de pesquisadores/as brasileiros/ as e internacionais, na medida em que oferece um panorama da diversidade do Serviço Social no mundo e "revela que a pluralidade de formatos forjada nas condições históricas de cada país assenta-se nas particularidades dos processos de (re)produção do capital e da questão social (Boschetti, 2019, s. p.).

As instigantes reflexões e análises apresentadas na obra a tornam leitura obrigatória para todos/as que buscam aprofundar, sob a ótica dos Fundamentos do Serviço Social, a apreensão das múltiplas determinações que incidem sobre a profissão e a sua diversidade histórico-profissional ao redor do mundo.

\section{Referências}

ÁVILA, Roberth Salamanca; LONDOÑO, Sergio Andrés Quintero. O Serviço Social na Colômbia: história e contemporaneidade. In: YAZBEK, Maria Carmelita; IAMAMOTO, Marilda Villela (org.). Serviço Social na história: América Latina, África e Europa. São Paulo: Cortez, 2019. p. 242-268.

BEHRING, Elaine. Orelha. In: YAZBEK, Maria Carmelita; IAMAMOTO, Marilda Villela (org.). Serviço Social na história: América Latina, África e Europa. São Paulo: Cortez, 2019.

BOSCHETTI, Ivanete. Quarta capa. In: YAZBEK, Maria Carmelita; IAMAMOTO, Marilda Villela (org.). Serviço Social na história: América Latina, África e Europa. São Paulo: Cortez, 2019.

GOIN, Marileia. Fundamentos do Serviço Social na América Latina e no Caribe: conceituação, condicionantes sócio-históricos e particularidades profissionais. São Paulo: Papel Social, 2019a.

GOIN, Marileia. Tendências atuais no ensino dos Fundamentos do Serviço Social. Textos \& Contextos, Porto Alegre, v. 18, n. 2, p. 1-12, jul./dez. 2019b.

IAMAMOTO, Marilda Villela. O Serviço Social brasileiro em tempos de mundialização do capital. In: YAZBEK, Maria Carmelita; IAMAMOTO, Marilda Villela (org.). Serviço Social na história: América Latina, África e Europa. São Paulo: Cortez, 2019. p. 34-61.

IAMAMOTO, Marilda Villela; YAZBEK, Maria Carmelita. Introdução. In: YAZBEK, Maria Carmelita; IAMAMOTO, Marilda Villela (org.). Serviço Social na história: América Latina, África e Europa. São Paulo: Cortez, 2019. p. 11-30.

MARTINELLI, Maria Lúcia. Serviço Social: identidade e alienação. 8. ed. São Paulo: Cortez, 2003. 
MARTINS, Alcina; TOMÉ, Maria Rosa. Neoliberalismo e Serviço Social português: impactos de Bolonha e das políticas de austeridade na formação e no trabalho. In: YAZBEK, Maria Carmelita; IAMAMOTO, Marilda Villela (org.). Serviço Social na história: América Latina, África e Europa. São Paulo: Cortez, 2019. p. 384-408.

MIRANDA ARANDA, Miguel. De la caridad a la ciencia: pragmatismo, interaccionismo simbólico y trabajo social. 2. ed. Zaragoza: Mira Editores, 2009.

MONTEIRO, Amor António. Serviço Social em Angola: gênese, tendências teórico-metodológicas e desafios. In:YAZBEK, Maria Carmelita; IAMAMOTO, Marilda Villela (org.). Serviço Social na história: América Latina, África e Europa. São Paulo: Cortez, 2019. p. 363-380.

NETTO, José Paulo. Ditadura e Serviço Social: uma análise do Serviço Social no Brasil pós64. 11. ed. São Paulo: Cortez, 2007.

RAICHELIS, Raquel. O trabalho do assistente social na esfera estatal. In: CONSELHO FEDERAL DE SERVIÇO SOCIAL (CFESS); ASSOCIAÇÃO BRASILEIRA DE ENSINO E PESQUISA EM SERVIÇO SOCIAL (ABEPSS). Serviço Social: direitos sociais e competências profissionais. Brasília: CFESS/ABEPSS, 2009. p. 377-392.

RAICHELIS, Raquel. O Serviço Social no Brasil: trabalho, formação profissional e projeto ético-político. In: YAZBEK, Maria Carmelita;
IAMAMOTO, Marilda Villela (org.). Serviço Social na história: América Latina, África e Europa. São Paulo: Cortez, 2019. p. 62-85.

SANTO, Felisbela A. Espírito. Serviço Social em Angola. In: YAZBEK, Maria Carmelita; IAMAMOTO, Marilda Villela (org.). Serviço Social na história: América Latina, África e Europa. São Paulo: Cortez, 2019. p. 340-362.

YAZBEK, Maria Carmelita. Serviço Social e seu projeto ético-político em tempos de devastação: resistências, lutas e perspectivas. In: YAZBEK, Maria Carmelita; IAMAMOTO, Marilda Villela (org.). Serviço Social na história: América Latina, África e Europa. São Paulo: Cortez, 2019. p. 86-101.

YAZBEK, Maria Carmelita; IAMAMOTO, Marilda Villela. Posfácio. In: YAZBEK, Maria Carmelita; IAMAMOTO, Marilda Villela (org.). Serviço Social na história: América Latina, África e Europa. São Paulo: Cortez, 2019. p. 511-520.

\section{Sobre a autora}

Marileia GoIn - Assistente social, Mestre e Doutora em Serviço Social. Professora da Graduação e da Pós-Graduação do Departamento de Serviço Social. Líder do Grupo de Estudos e Pesquisas sobre Fundamentos do Serviço Social e América Latina.

E-mail: mari.goin84@gmail.com 